\title{
Mechanisms of Unexplained Anemia in the Nursing Home
}

\author{
Andrew S. Artz, MD, ${ }^{* \dagger}$ Dean Fergusson, MHA, PhD, ${ }^{\dagger \mathcal{S}}$ Paul J. Drinka, MD, ${ }^{\dagger}$ Melvin Gerald, MD, ${ }^{\dagger *}$ \\ Rex Bidenbender, MD,${ }^{\dagger * *}$ Anthony Lechich, MD,${ }^{\dagger \dagger}$ Felix Silverstone, MD, ${ }^{\dagger \ddagger}$ Mark A. McCamish, \\ MD, PhD, ${ }^{\mathcal{S}}$ Jinlu Dai, MD, PhD, " Evan Keller, DVM, PhD, ${ }^{\# \#}$ and William B. Ershler, MD ${ }^{* \dagger \dagger}$
}

OBJECTIVES: To characterize anemia in elderly nursing home residents.

DESIGN: Prospective multiinstitutional cohort study.

SETTING: Five nursing homes.

PARTICIPANTS: From retrospective analysis, residents found to be anemic using chart review were prospectively randomized. Of the 81 residents enrolled, 60 were anemic. MEASUREMENTS: Chart review for medical history and factors related to treatment or history of anemia, extensive laboratory evaluation for causes of anemia, and classification of anemia by two hematologists.

RESULTS: Among the 60 anemic residents, the causes of anemia were idiopathic $(n=27)$, iron-deficiency $(n=14)$, anemia associated with chronic disease $(\mathrm{n}=8)$, anemia of renal insufficiency $(n=6)$, and other $(n=5)$. The eryrthropoietin (EPO) response to anemia was lower in residents with idiopathic anemia (IA) than in those with irondeficiency anemia, and this correlated with renal function as estimated using calculated creatinine clearance. In this elderly population, advancing age was not correlated with lower EPO response.

From the *Institute for Advanced Studies in Aging and Geriatric Medicine, Washington, DC; ${ }^{\dagger}$ National Geriatrics Research Consortium, Washington, DC; ${ }^{\ddagger}$ University of Chicago Medical Center, Chicago, Illinois; ${ }^{\S}$ Ottawa Hospital Research Institute, Ottawa, Canada; "Wisconsin Veterans Home, King, Wisconsin; "Washington Nursing Facility, Washington, DC; ${ }^{* *}$ Eastern Virginia Medical School, Norfolk, Virginia; ${ }^{\dagger \dagger}$ Center Terence Cardinal Cooke Health Care Center, New York, New York; ${ }^{\ddagger \ddagger}$ Parker Jewish Institute for Health Care and Rehabilitation, New Hyde Park, New York; ${ }^{\circledR}$ Amgen, Inc., Thousand Oaks, California; and "Program of Immunology and ${ }^{\# \#}$ Department of Pathology, University of Michigan, Ann Arbor, Michigan.

Support for this study was provided in part by a grant from Amgen Inc. and in part from National Institutes of Health Grant AG-15884. This work was presented at the International Conference on Immunology and Aging in Washington, DC, in June 2002. Drs. Ershler and Artz have served as consultants for Amgen in the area of anemia. Drs. Ershler and Artz and Mr. Fergusson are involved in other studies supported by Amgen. Amgen Inc. markets several recombinant erythropoietin molecules. Drs. Ershler, Artz, and Silverstone have been involved in studies supported by Johnson and Johnson. Ortho Biotech, a division of Johnson and Johnson, markets an epoetin alfa preparation. Amgen provided input on the design of the study and the final manuscript.

Address correspondence to Andrew S. Artz, MD, 5841 South Maryland Avenue, MC 2115, Chicago, IL 60637.

E-mail: aartz@medicine.bsd.uchicago.edu
CONCLUSION: IA is common in nursing home residents. A lower EPO response contributes to the high prevalence of anemia in this setting and may be due, in part, to occult renal dysfunction. J Am Geriatr Soc 52:423-427, 2004.

Key words: elderly; anemia; erythropoietin; renal insufficiency; frail

A nemia is common in nursing home residents, with prevalence rates between $20 \%$ and $40 \% .^{1-3}$ Although often underappreciated, even mild anemia in the elderly is associated with increased morbidity and mortality. ${ }^{4,5}$

Limited data are available that define the causes of anemia in nursing home residents. Single institutional studies suggest that $40 \%$ of anemic residents exhibit iron deficiency anemia (IDA). ${ }^{1,3}$ In older people in general, the causes of anemia vary depending on the clinical setting. In community-dwelling or hospitalized older persons, IDA and chronic inflammation are the most common observed factors. ${ }^{6}$ No defined etiology (idiopathic anemia (IA)) has been reported in $15 \%$ of such subjects. ${ }^{7-9}$

With the development and usage of serum ferritin and erythropoietin (EPO) assays, more precise anemia classification has become possible. Serum ferritin has proven instrumental in diagnosing IDA ${ }^{10}$ and often obviates the need for assessment of iron stores using bone marrow biopsy. Soluble transferrin receptor may have additional utility because it is elevated in IDA but not with the erythroid hypoplasia of chronic inflammation. ${ }^{11}$ EPO, a renally secreted glycopeptide hormone that stimulates erythropoiesis, normally rises dramatically in response to anemia. In many chronic conditions, such as cancer and rheumatoid arthritis, ${ }^{12,13}$ the endogenous EPO response to anemia is inadequate, or blunted, to counteract the anemia. Furthermore, conflicting data exist as to whether ${ }^{14-19}$ or not $^{20,21}$ anemic older persons have a relative EPO deficiency.

A multiinstitutional study was conducted to characterize anemia in a diverse population of elderly nursing home residents. 


\section{METHODS}

\section{Informed Consent}

This study was implemented under the administrative auspices of the National Geriatrics Research Consortium. A centralized institutional review board (IRB) and, when available, a facility-specific IRB approved the protocol. Each subject or guardian provided informed consent. An informational video supplemented the informed consent process.

\section{Subject Selection}

An initial chart review of all subjects from five skillednursing facilities was conducted to identify all anemic subjects as defined using World Health Organization criteria (hemoglobin $(\mathrm{Hb})<13 \mathrm{~g} / \mathrm{dL}$ for men and $<12 \mathrm{~g} /$ $\mathrm{dL}$ for women). Of the 900 evaluable subjects, 433 were anemic. Of those identified as anemic, 100 subjects, 20 from each facility, were randomly selected for further analysis. Additional randomly selected subjects were enrolled when the original lists were exhausted because subjects were unavailable (hospitalized, deceased) or informed consent was not obtained.

\section{Anemia Evaluation}

A chart review and laboratory analysis for each enrolled subject was performed. Laboratory testing included complete blood count with differential, reticulocyte count, total bilirubin, gamma glutamyl transpeptidase, aspartate aminotransferase, L-alanine aminotransferase, albumin, iron, total iron binding capacity, ferritin, C-reactive protein (CRP), folic acid, vitamin $\mathrm{B}_{12}$, thyrotropin-stimulating hormone, and EPO level. Testing for methylmalonic acid was performed for vitamin $B_{12}$ less than $300 \mathrm{pg} / \mathrm{mL}$ and for soluble transferrin for ferritin between 18 and $100 \mathrm{ng} / \mathrm{mL}$. Interleukin (IL)-6 was assayed when serum was available. Two investigators (ASA and WBE) independently classified the anemia using the medical history and laboratory parameters. Discrepancies occurred in fewer than $10 \%$ of cases, and conflicts were resolved using further data review and consensus development. IDA was determined using iron studies and ferritin, soluble transferrin receptor, and CRP levels. Anemia due to renal insufficiency was diagnosed when the calculated creatinine clearance was less than $30 \mathrm{~mL} / \mathrm{min}$ (using the Cockcroft formula ${ }^{22}$ ) or serum creatinine was greater than $2.0 \mathrm{mg} / \mathrm{dL}$. Although, in some subjects, more than one causative factor was likely (e.g., IDA and chronic inflammation), each subject was given one diagnosis to account for the anemia. IA was diagnosed if no other causative factors were apparent.

\section{Statistical Analysis}

Statistical analyses were conducted using NCSS (2000 Version, Cruncher Statistical Systems, Kaysville, UT). Univariate descriptive statistics, including measures of central tendency and dispersion, were calculated for overall demographic and laboratory values and separately by type of anemia. Comparisons between anemia types were calculated with independent $t$ tests (equivalent nonparametric procedures when standard assumptions are not met) for continuous data and chi-square tests for categorical data. Multivariate linear regression modeling techniques were used to explain the association between EPO levels and $\mathrm{Hb}$ values while adjusting for age and sex. Because EPO levels were not normally distributed, the natural log of the value was chosen.

\section{RESULTS}

\section{Study Subjects}

Eighty-three subjects agreed to participate in this study and had laboratory tests completed. Of the 83,81 had complete and adequate laboratory analysis; of these, laboratory results confirmed anemia in $60(74 \%)$. Of the 60 anemic subjects, $28(48 \%)$ had a charted diagnosis of anemia. The median age was 82 (range 49-94), and $23(40 \%$ ) were male. Seventy percent were Caucasian, and $28 \%$ were African American.

\section{Causes of Anemia}

IDA was identified in $14(23 \%)$, anemia of chronic disease in eight $(13 \%)$, and renal insufficiency in six $(10 \%)$. A cytopenia outside of the red blood cell lineage led three subjects to be classified with presumed bone marrow failure/myelodysplasia. Other causes of anemia included one subject with hypothyroidism and one with a hemoglobinopathy. No explanation was uncovered in 27 (45\%), and these were classified as IA. Of those with moderate anemia, a cause was determined for seven $(64 \%)$.

\section{Red Blood Cell Parameters}

The mean $\mathrm{Hb}$ value was $10.5 \mathrm{~g} / \mathrm{dL}$ ( $95 \%$ confidence interval $(\mathrm{CI})=10.2-10.8)$ for women and $11.1 \mathrm{~g} / \mathrm{dL} \quad(95 \%$ $\mathrm{CI}=10.6-11.6)$ for men. Microcytic, normocytic, and macrocytic red blood cell indices were identified in four, 10 , and 0 IDA subjects and 0,24, and three of IA subjects, respectively. More severe anemia, defined as a Hb less than $10 \mathrm{~g} / \mathrm{dL}$, was found in $11(19 \%)$ patients.

\section{Erythropoietin}

Figure 1 plots EPO levels against hemoglobin for the three most common types of anemia: anemia of chronic disease, idiopathic anemia, and iron-deficiency anemia. Table 1 shows the mean EPO levels for IDA and IA of $29.0 \mathrm{mIU} / \mathrm{mL}$ and $14.6 \mathrm{mIU} / \mathrm{mL}$, respectively $(P<.001)$. When adjusting for age, sex, and $\mathrm{Hb}$, there was a significant difference in EPO levels between those with IDA and those with IA $(P=.003)$. In the anemic residents with adequate renal function $(>30 \mathrm{~mL} / \mathrm{min}$ calculated creatinine clearance or serum creatinine $>2.0 \mathrm{~g} / \mathrm{dL}$ ), calculated creatinine clearance was independently associated with lower EPO levels when controlling for age, sex, and $\mathrm{Hb}(P=.008)$. Age had no independent effect on $\mathrm{Hb}$ for all anemic subjects $(P=.57)$ or for IA subjects only $(P=.18)$.

\section{Interleukin-6}

IL-6 levels were obtained from 32 of 60 samples (Table 1). The IL-6 levels were markedly elevated in those with anemia of chronic disease (ACD). Small nonsignificant differences existed between the IL-6 levels of those with IA $(8.5 \mathrm{pg} / \mathrm{mL})$ and those with IDA $(6.6 \mathrm{pg} / \mathrm{mL})$. 


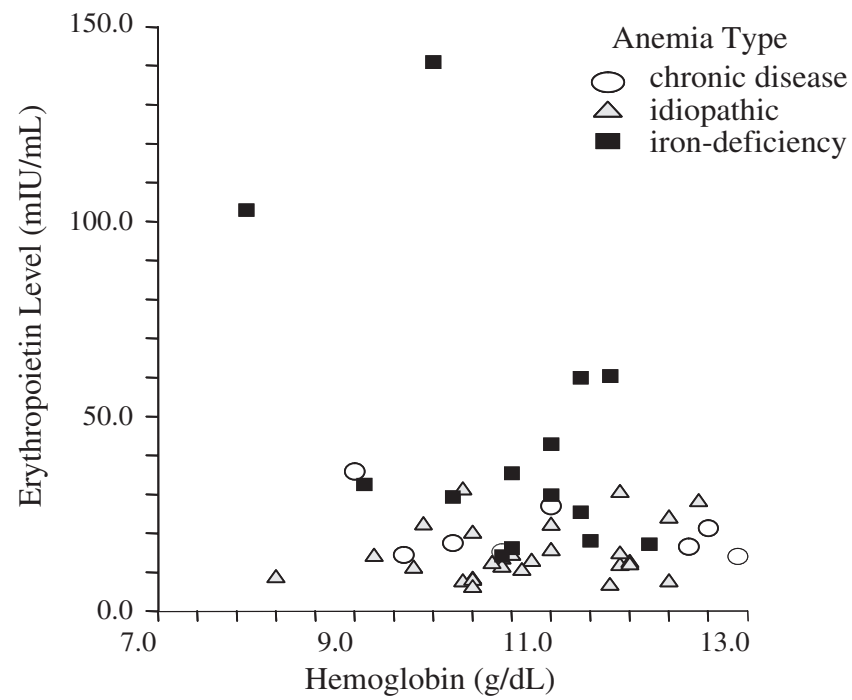

Figure 1. Endogenous erythropoietin levels and hemoglobin values of subjects with different types of anemia.

\section{DISCUSSION}

This is the first study employing current laboratory assays to rigorously characterize anemia in institutionalized elderly residents. Single institutional studies of nursing home residents using less rigorous criteria have reported IDA in $40 \%$ of anemic residents ${ }^{1,3}$ whereas in this study, iron deficiency was found in only $23 \%$ of the anemic subjects. One reason less IDA might have been found was the incorporation of the serum ferritin assay, which, despite the limitation of being elevated with inflammation, provides a useful marker of total body iron stores. Previous reports had relied on serum iron, total iron binding capacity, and response to iron therapy. Another, and possibly equally important reason, is the changing profile of nursing home residents. Typically, nursing home residents are more likely to be frail and afflicted with several comorbidities than noninstitutionalized elderly, thereby altering the distribution of anemia types in favor of mechanisms other than simple iron deficiency. It might be postulated that iron deficiency is more frequently recognized, investigated, and treated in the community than in previous surveys.

Only $29 \%$ of subjects with a diagnosis of IDA had microcytosis, although they met all other criteria for iron deficiency. The mean serum ferritin was only $22.5 \mathrm{ng} / \mathrm{mL}$, well below the level of $50 \mathrm{ng} / \mathrm{mL}$ considered diagnostic of iron deficiency in elderly populations. ${ }^{10}$ The absence of the characteristic microcytosis of IDA may reflect the multiplicity of mechanisms accounting for inadequate erythropoiesis in frail populations. It is possible, for example, that inflammatory disease, nutritional inadequacies, or a sluggish EPO response all contribute to the red cell inadequacy, and this combined picture might favor a mixed red cell population, skewing the mean corpuscular volume into a more normal range. Another possibility is that microcytic anemia prompted an evaluation and corrective therapy, whereas normocytic anemia did not, reducing the proportion of microcytic IDA residents. The data suggest that IDA should be considered even in the presence of normocytic anemia.

This survey uncovered fewer-than-expected patients with ACD. This, too, may relate to the more comprehensive analysis undertaken. Frail elderly anemic nursing home residents without obvious cause (e.g., iron, $\mathrm{B}_{12}$, folate, or thyroid deficiency; renal failure; myelodysplasia) commonly receive a default diagnosis of ACD disease, but in the current study, based on biochemical markers of inflammation (CRP, IL-6) and chart review, only eight anemic patients met criteria for ACD.

In contrast, IA was found in $27(45 \%)$ anemic residents. Studies in noninstitutionalized elderly persons have demonstrated a $15 \%$ prevalence of IA. ${ }^{7-9}$ Although no anemic subjects characterized as idiopathic had apparent abnormalities of white blood cells or platelets based on the peripheral smear, without a bone marrow evaluation, subtle bone marrow failure states cannot be excluded, and perhaps some patients characterized with IA had early myelodysplasia.

Table 1. Mean Erythropoietin Levels and Related Parameters for Anemic Nursing Home Residents

\begin{tabular}{|c|c|c|c|c|c|c|c|}
\hline & $\begin{array}{l}\text { Hemoglobin, } \\
\text { g/dL* }\end{array}$ & $\begin{array}{l}\text { Erythropoietin, } \\
\text { mIU/mL }\end{array}$ & $\begin{array}{c}\text { Mean } \\
\text { Corpuscular } \\
\text { Volume, } \mathrm{fL}^{\ddagger}\end{array}$ & $\begin{array}{l}\text { Ferritin, } \\
\mathrm{ng} / \mathrm{mL}^{\S}\end{array}$ & $\begin{array}{l}\text { Interleukin-6, } \\
\mathrm{pg} / \mathrm{mL}^{\|}\end{array}$ & $\begin{array}{l}\text { Albumin, } \\
\text { g/dL }\end{array}$ & $\begin{array}{c}\text { C-Reactive } \\
\text { Protein, } \\
\text { mg/dL" }\end{array}$ \\
\hline Type & \multicolumn{7}{|c|}{ Mean \pm Standard Deviation } \\
\hline $\begin{array}{l}\text { Iron deficiency anemia } \\
\qquad(\mathrm{n}=14)\end{array}$ & $10.6 \pm 1.1$ & $29.0 \pm 16.2$ & $85.4 \pm 7.0$ & $22.5 \pm 14.5$ & $6.6 \pm 2.7$ & $3.7 \pm 0.5$ & $10.1 \pm 15.4$ \\
\hline $\begin{array}{l}\text { Anemia of chronic disease } \\
\qquad(\mathrm{n}=8)\end{array}$ & $11.0 \pm 1.5$ & $20.3 \pm 7.6$ & $93.1 \pm 3.4$ & $167.4 \pm 79.1$ & $44.3 \pm 72.4$ & $3.6 \pm 0.4$ & $36.9 \pm 35.5$ \\
\hline $\begin{array}{l}\text { Idiopathic anemia } \\
\qquad(\mathrm{n}=27)\end{array}$ & $10.8 \pm 1.0$ & $14.6 \pm 7.3$ & $92.3 \pm 5.9$ & $201.6 \pm 195.6$ & $8.5 \pm 7.8$ & $3.6 \pm 0.3$ & $6.0 \pm 5.0$ \\
\hline Other** $(n=5)$ & $10.0 \pm 1.2$ & $13.4 \pm 1.6$ & $87.0 \pm 9.3$ & $356.0 \pm 577.1$ & $98.0 \pm 106.8$ & $3.6 \pm 0.3$ & $41.1 \pm 68.7$ \\
\hline $\begin{array}{l}\text { Chronic renal insufficiency** } \\
\qquad(n=6)\end{array}$ & $11.5 \pm 0.8$ & $12.5 \pm 4.2$ & $89.5 \pm 6.5$ & $177.8 \pm 215.9$ & $7.5 \pm 1.4$ & $3.9 \pm 0.3$ & $8.3 \pm 5.6$ \\
\hline All $(n=60)$ & $10.7 \pm 1.1$ & $18.6 \pm 11.6$ & $90.1 \pm 6.7$ & $166.9 \pm 233.6$ & $19.0 \pm 41.0$ & $3.7 \pm 0.4$ & $13.6 \pm 25.7$ \\
\hline
\end{tabular}

Reference range: ${ }^{*} 11.5-15.0 ;{ }^{\dagger} 4.2-27.8 ;{ }^{\ddagger} 80-98 ;{ }^{\S} 10-291 ; " \| 0.447-9.96 ;{ }^{`} 3.5-4.8 ;{ }^{\#} 0-4.9$.

${ }^{* *}$ No etiology of anemia uncovered. 
Modest reductions in glomerular filtration rate are associated with anemia. ${ }^{23}$ Thus, to classify IA as a separate entity from the anemia of chronic renal insufficiency (CRI), a stringent CRI definition was employed $(<30 \mathrm{~mL} / \mathrm{min}$ calculated creatinine clearance or serum creatinine $>2.0$ $\mathrm{mg} / \mathrm{dL}$ ). Of those with IA, the mean serum creatinine was $1.0 \mathrm{mg} / \mathrm{dL}$, and mean calculated creatinine clearance was $57 \mathrm{~mL} / \mathrm{min}$, but a low serum EPO level in patients with anemia may in itself be evidence of insufficiency of renal endocrine function. Because renal interstitial cells, not glomeruli or tubular cells, are the source of renal EPO, ${ }^{24} \mathrm{a}$ disconnect may exist between the capacity for nephron (glomerular and tubular) function and renally mediated homeostasis of erythropoiesis. Alternatively, diminished EPO levels may predict incipient renal deterioration, as has been suggested happens in diabetic nephropathy. ${ }^{25}$

Protein-calorie malnutrition is commonly found in nursing home residents and may be associated with anemia. ${ }^{26,27}$ This was investigated as a possible cause for the anemia in the IA group, but the nonanemic and IA residents had similar mean \pm standard deviation albumin $(3.6 \pm 0.3 \mathrm{~g} / \mathrm{dL}$ and $3.8 \pm 0.4 \mathrm{~g} / \mathrm{dL}$, respectively) and weight $(67.6 \pm 16.6 \mathrm{~kg}$ and $70.2 \pm 21.3 \mathrm{~kg}$, respectively), indicating that protein-calorie malnutrition was unlikely to be responsible for IA in this study. Similarly, and surprisingly, the current study did not detect any patients with vitamin $B_{12}$ or folic acid deficiency. This probably reflects common testing for nutrient deficiencies in at-risk populations and the frequent use of vitamin $\mathrm{B}_{12}$ supplementation.

Awareness of endogenous EPO levels has become instrumental in understanding chronic hypoproliferative anemias. Determining the appropriateness of the EPO response relative to the degree of anemia remains challenging. In healthy young adults, EPO increases dramatically in response to hypoxia or anemia. A blunted response has been well demonstrated in chronic conditions such as cancer and rheumatoid arthritis. ${ }^{12,13}$ Research involving experimental animal models has indicated that erythropoietic response is lower with advancing age. ${ }^{28,29}$ Some clinical trials have suggested lower EPO responsiveness with advancing age, ${ }^{15,19}$ whereas others have not. ${ }^{20,21} \mathrm{EPO}$ levels in elderly persons with IA have not been well studied because most prior reports included patients with iron deficiency or chronic inflammation. In older communitydwelling subjects with "senile" anemia, defined as lack of iron or $\mathrm{B}_{12}$ or folate deficiency, another study suggested a blunted EPO response. ${ }^{17}$ Similar predictions have been suggested in older persons upon subgroup analysis of those with normocytic anemia. ${ }^{16}$

The data from the current study strongly suggest that nursing home residents with IA have a blunted endogenous EPO response. The mean EPO of residents with IA was lower than that of those with IDA, despite similar Hb levels $(P<.001)$. In contrast to those with IDA, univariate analysis of IA shows no correlation with $\mathrm{Hb}$ levels, suggesting a lack of responsiveness to declining $\mathrm{Hb}$ in this group (Figure 2). In the small ACD group, the low mean EPO levels are supportive of reduced responsiveness, whereas in the IDA residents, the elevated mean EPO levels and the relatively strong $\mathrm{EPO} / \mathrm{Hb}$ correlation indicate some degree of preserved EPO responsiveness. The results are consistent with previous data in noninstitutionalized elderly persons showing less responsiveness in subjects with ACD than in those with IDA (controls). ${ }^{17,18}$ The EPO response in IDA residents may still be inadequate, albeit to a lesser degree than in those with IA. A younger IDA control group would be required to confirm this. For example, one study has shown a lower EPO response in elderly patients with IDA than in younger patients with IDA, but only at $\mathrm{Hb}$ values less than $10.0 \mathrm{~g} / \mathrm{dL} .{ }^{15}$

The blunted EPO response appears to play an important, if not central role, in the high prevalence of IA found in this population. It is possible that shortened red blood cell survival, occult blood loss, or subtle nutrient deficiencies may serve as erythropoietic stressors for which the EPO response is inadequate. Alternatively, a primary deficiency in EPO secretion might result in reduced $\mathrm{Hb}$ levels independent of other causes of anemia. Whether primary or secondary, a major question is what accounts for the observed EPO deficiency in those with IA. A potential explanation relates the observed cytokine dysregulation with age, ${ }^{9}$ including circulating levels of proinflammatory cytokines, which have been shown under experimental circumstances to inhibit erythropoiesis. ${ }^{30}$ Cytokine dysregulation alone is not sufficient to completely explain IA, because CRP and IL-6 were the same or higher in IDA residents who did respond with elevated EPO levels. This suggests that high levels of inflammation are not solely
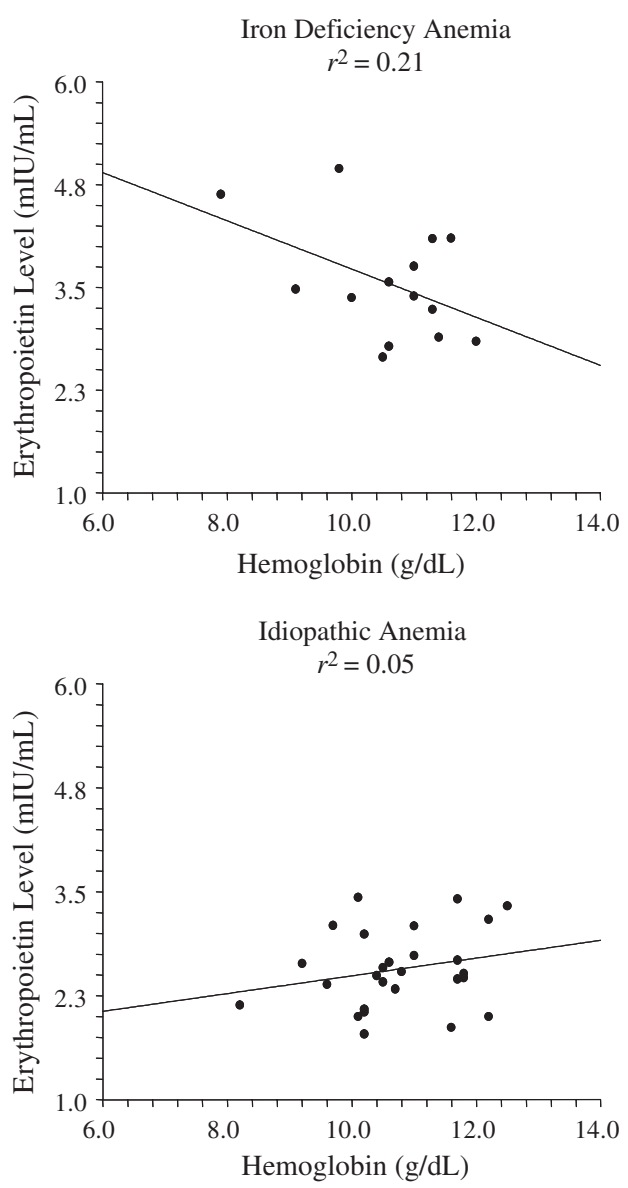

Figure 2. Correlations between natural log transformed erythropoietin levels and hemoglobin comparing variances $\left(r^{2}\right)$ of patients with iron-deficiency anemia and idiopathic anemia. 
implicated. A more complete cytokine evaluation, including IL-1 and tumor necrosis factor, is needed to better evaluate the role of an age-related dysregulation of these inflammatory mediators in the pathogenesis of IA. Bone marrow unresponsiveness is an unlikely explanation for IA. If marrow failure were common, EPO levels would be expected to be high, not low as was observed. It is believed that age alone does not reduce bone marrow responsiveness, at least to pharmacological doses of exogenous recombinant human EPO. ${ }^{21,31}$ Bone marrow unresponsiveness is often a prominent feature in cancer patients, in whom elevated levels of endogenous EPO, albeit lower than in matched iron-deficient patients, are often found.

In summary, IA is the most common type of anemia in elderly nursing home residents, and this is due, at least in part, to a blunted EPO response. The mechanism of inadequate EPO response requires more study, specifically applying more sensitive measures of renal function and a complete cytokine evaluation. With recombinant human erythropoietin ( $\mathrm{rHuEPO})$ clinically available, practical considerations for treatment options arise. The issue becomes more germane because compelling evidence has demonstrated that correction of anemia associated with many chronic conditions decreases morbidity and possibly mortality. A rationale for interventional trials exists considering the high prevalence of IA and its associated EPO deficiency: a clinical situation similar to the anemia of advanced renal disease. Furthermore, $\mathrm{rHuEPO}$ in moderate renal insufficiency not only corrects anemia but may also slow progression of renal failure. ${ }^{32}$ Improvement of anemia with low doses of rHuEPO, such as used in renal failure, would provide further evidence that low EPO levels, rather than bone marrow unresponsiveness, are implicated in elderly nursing home residents.

\section{REFERENCES}

1. Chen LH, Cook-Newell ME. Anemia and iron status in the free-living and institutionalized elderly in Kentucky. Int J Vitam Nutr Res 1989;59:207-213.

2. Chernetsky A, Sofer O, Rafael C et al. Prevalence and etiology of anemia in an institutionalized geriatric population. Harefuah 2002;141:591-594, 667.

3. Kalchthlaer T, Tan ME. Anemia in institutionalized elderly patients. J Am Geriatr Soc 1980;28:108-113.

4. Izaks GJ, Westendorp RG, Knook DL. The definition of anemia in older persons. JAMA 1999;281:1714-1717.

5. Chaves PH, Ashar B, Guralnik JM et al. Looking at the relationship between hemoglobin concentration and prevalent mobility difficulty in older women. Should the criteria currently used to define anemia in older people be reevaluated? J Am Geriatr Soc 2002;50:1257-1264.

6. Joosten E, Pelemans W, Hiele M et al. Prevalence and causes of anaemia in a geriatric hospitalized population. Gerontology 1992;38:111-117.

7. Kirkeby OJ, Fossum S, Risoe C. Anaemia in elderly patients. Incidence and causes of low haemoglobin concentration in a city general practice. Scand J Prim Health Care 1991;9:167-171.
8. Ania BJ, Suman VJ, Fairbanks VF et al. Incidence of anemia in older people: An epidemiologic study in a well-defined population. J Am Geriatr Soc 1997;45: $825-831$.

9. Baraldi-Junkins CA, Beck AC, Rothstein G. Hematopoiesis and cytokines. Relevance to cancer and aging. Hematol Oncol Clin North Am 2000;14: 45-61.

10. Joosten E, Hiele M, Ghoos Y et al. Diagnosis of iron-deficiency anemia in a hospitalized geriatric population. Am J Med 1991;90:653-654.

11. Joosten E, Van Loon R, Billen J et al. Serum transferrin receptor in the evaluation of the iron status in elderly hospitalized patients with anemia. Am J Hematol 2002;69:1-6.

12. Miller CB, Jones RJ, Piantadosi S et al. Decreased erythropoietin response in patients with the anemia of cancer. N Engl J Med 1990;322:1689-1692.

13. Boyd HK, Lappin TR, Bell AL. Evidence for impaired erythropoietin response to anaemia in rheumatoid disease. Br J Rheumatol 1991;30:212-213.

14. Kario K, Matsuo T, Nakao K. Serum erythropoietin levels in the elderly. Gerontology 1991;37:345-348.

15. Nafziger J, Pailla K, Luciani L et al. Decreased erythropoietin responsiveness to iron deficiency anemia in the elderly. Am J Hematol 1993;43:172-176.

16. Carpenter MA, Kendall RG, O'Brien AE et al. Reduced erythropoietin response to anemia in elderly patients with normocytic anaemia. Eur J Haematol 1992;49:119-121.

17. Kario K, Matsuo T, Kodoma K et al. Reduced erythropoietin secretion in senile anemia. Am J Hematol 1992;41:252-257.

18. Joosten E, Van Hove L, Lesaffre E et al. Serum erythropoietin levels in elderly inpatients with anemia of chronic disorders and iron deficiency anemia. J Am Geriatr Soc 1993;41:1301-1304.

19. Matsuo T, Kario K, Kodoma K et al. An inappropriate erythropoietic response to iron deficiency anaemia in the elderly. Clin Lab Haematol 1995;17:317321.

20. Powers JS, Krantz SB, Collins JC et al. Erythropoietin response to anemia as a function of age. J Am Geriatr Soc 1991;39:30-32.

21. Goodnough LT, Price TH, Parvin CA. The endogenous erythropoietin response and erythropoietic response to blood loss anemia: The effects of age and gender. J Lab Clin Med 1995;126:57-64.

22. Cockcroft DW, Gault MH. Prediction of creatinine clearance from serum creatinine. Nephron 1976;16:31-41.

23. Hsu CY, McCulloch CE, Curhan GC. Epidemiology of anemia associated with chronic renal insufficiency among adults in the United States: Results from the Third National Health and Nutrition Examination Survey. J Am Soc Nephrol 2002;13:504-510.

24. Maxwell PH, Osmond MK, Pugh CW et al. Identification of the renal erythropoietin-producing cells using transgenic mice. Kidney Int 1993;44: 1149-1162.

25. Inomata S, Itoh M, Imai H et al. Serum levels of erythropoietin as a novel marker reflecting the severity of diabetic nephropathy. Nephron 1997;75:426430.

26. Abbasi AA, Rudman D. Observations on the prevalence of protein-calorie undernutrition in VA nursing homes. J Am Geriatr Soc 1993;41:117-121.

27. Rudman D, Feller AG. Protein-calorie undernutrition in the nursing home. J Am Geriatr Soc 1989;37:173-183.

28. Udupa KB, Lipschitz DA. Erythropoiesis in the aged mouse: II. Response to stimulation in vitro. J Lab Clin Med 1984;103:581-588.

29. Udupa KB, Lipschitz DA. Erythropoiesis in the aged mouse: I. Response to stimulation in vivo. J Lab Clin Med 1984;103:574-580.

30. Jelkmann WE, Fandrey J, Frede $S$ et al. Inhibition of erythropoietin production by cytokines. Implications for the anemia involved in inflammatory states. Ann N Y Acad Sci 1994;718:300-309, discussion 309-311.

31. Shank WA Jr, Balducci L. Recombinant hemopoietic growth factors. Comparative hemopoietic response in younger and older subjects. J Am Geriatr Soc 1992;40:151-154.

32. Jungers P, Choukroun G, Oualim Z et al. Beneficial influence of recombinant human erythropoietin therapy on the rate of progression of chronicrenal failure in predialysis patients. Nephrol Dial Transplant 2001;16: 307-312. 